\title{
Stress, Anxiety Levels and Decision Making Styles of South African Senior Learners: Results of a Science Fair Project
}

\author{
Nicole Masureik ${ }^{1}$, Nicolette Vanessa Roman, ${ }^{2,}$, Nicholas Jody Roman ${ }^{3}$ \& Aadam Toefy ${ }^{3}$ \\ ${ }^{1}$ Science Educator at the Secondary School, Cape Town, South Africa \\ ${ }^{2}$ Child and Family Studies, Social Work Department, University of the Western Cape, South \\ Africa \\ ${ }^{3}$ Senior learners at the Secondary School, Cape Town, South Africa \\ *Corresponding author: Child and Family Studies, Social Work Department, University of \\ the Western Cape, South Africa. E-mail: nicoletteroman@gmail.com
}

Received: April 28, $2014 \quad$ Accepted: June 4, $2014 \quad$ Published: August 13, 2014

doi:10.5296/ije.v6i3.6128ＵRL: http://dx.doi.org/10.5296/ije.v6i3.6128

\begin{abstract}
This study sought to determine the influence of stress and anxiety on the way in which senior learners make decisions. Although decision-making is generally important for senior learners, making decisions become more important because they are completing school and heading for different careers or just making more adult decisions in taking on more responsibilities. However, life is also stressful and can create anxiety especially in making decisions. This study used the Flinders Decision Making Questionnaire and the Depression, Anxiety and Stress Scale (DASS) to collect the data. A sample of 157 senior learners (Grade 10 to Grade 12) participated in the study. The majority were aged 16 , female (57.3\%), identified themselves as Coloured (60.5\%), spoke English as a home language (84.7\%) and lived with both parents. The results of this study show that senior learners use a vigilant decision-making style. When senior learners have increased stress and anxiety there is a possibility that they will use a hypervigilant decision-making style. When their anxiety increases then they could use a defensive avoidance decision-making style.
\end{abstract}

Keywords: Decision-making styles, Vigilance, Procrastination, Stress, Anxiety, Learners, Scholars, Secondary school, Education 


\section{Introduction}

Decision-making is identified as the ability to choose alternatives based on the values and preferences for a given object (French, West, Elander \& Wilding, 1993). It is also a process of making choices among competing courses of action. The ability to make decisions is the criterion for taking responsibility for actions and making independent decisions about the future (Arnett, 1998). This is especially true for senior learners in secondary school as they move towards matric and need to make career choices and move towards being independent. The need to make decisions can be stressful and cause anxiety (Jan and Mann, 1977).

According to Janis and Mann (1997) the stress arising from making decisions could be due to a concern over loss of reputation and self-esteem if the decision goes wrong. Also the loss which could occur by making the incorrect decision could also add to the stress. They identified five basic patterns of coping with the stress generated by a difficult, potentially threatening decision:

- Unconflicted adherence. The decision maker ignores information about the risk of losses and decides, complacently, to continue the present course of action.

- Unconflicted change. The decision maker uncritically adopts whichever new course of action is most salient or most strongly recommended.

- Defensive avoidance. The decision maker escapes conflict by procrastinating, shifting responsibility to someone else, or constructing wishful rationalizations to bolster the least objectionable alternative. Each of these expressions of defensive avoidance is associated with incomplete and often biased evaluation of information, leading in turn to faulty decisions. Defensive avoidance is associated with high stress.

- Hypervigilance. The decision maker searches frantically for a way out of dilemmas. Due to time pressure, the decision maker impulsively seizes upon hastily contrived solutions that seem to promise immediate relief. The full range of consequences of choices is overlooked because of emotional excitement, perseveration, and limited attention. In its more extreme form, hyper-vigilance is a 'panic'-like state in which the decision maker vacillates between unpleasant alternatives. Hypervigilance is associated with severe emotional stress.

- Vigilance. The decision maker clarifies objectives to be achieved by the decision, canvasses an array of alternatives, searches painstakingly for relevant information, assimilates information in an unbiased manner, and evaluates alternatives carefully before making a choice. Vigilance is associated with a moderate level of psychological stress ( $\mathrm{p} 2$ ).

These patterns of coping can only occur in the presence or absence of three conditions. The three conditions are: (1) awareness of serous risks about preferred alternatives, (2) hope of finding a better alternative, and (3) belief that there is adequate time to search and deliberate before a decision is required (Mann, et al., 1997). Thus, when someone makes a decision, particular patterns are followed. These are hypervigilance, vigilance, defensive, procrastination, rational and buck passing decision-making styles.

Although, Janis and Mann (1977) suggest that decision-making is stressful, they also propose 
that decision-making under stress could be problematic. In appropriate decision-making, the person needs to look at all the information. This is indicated by a vigilant decision-making style "the decision maker searches painstakingly for relevant information, assimilates information in an unbiased manner and appraises alternatives carefully before making a choice" (Janis, 1982, 73). Keinan (1987) states that under severe stress, a person can become hypervigilant and this is seen in hasty, disorganized, and an incomplete evaluation of information leading to faulty decisions and post-decisional regret. A study conducted by Raghunathan and Pham (1999) shows the influence of affect on decision-making. The results from three different experiments in their study show that, in gambling decisions, as well as in job selection decisions, anxious individuals are biased in favour of low-risk/low-reward options and reduce uncertainty. There are six common internal causes of stress, which are an inability to accept uncertainty, pessimism, negative self-talk, unrealistic expectations, perfectionism, and a lack of assertiveness. There are also common signs of stress. These are:

- Cognitive (memory problems, inability to concentrate, poor judgement, seeing only the negative, anxiousness and constant worry).

- Emotional (moodiness, short temper, agitation, feeling overwhelmed, sense of loneliness and isolation and depression).

- $\quad$ Physical (aches and pains, diarrhoea or constipation, nausea, dizziness, chest pain and rapid heartbeat, loss of sex drive and frequent colds).

- Behavioural (eating more or less, sleep too much or too little, isolation from others, procrastinating or neglecting responsibilities, using alcohol, cigarettes or drugs to relax and nerves habits such as biting nails or pacing).

Stress is an organism's response to a stressor such as an environmental condition or a stimulus. Stress is a body's way to react to a challenge. According to the stressful event, the body's way to respond to stress is by the sympathetic nervous system which results in the Fight-or-Flight response. Stress typically describes a negative condition or a positive condition that can have an impact on an organism's mental and physical well-being (Schneiderman, Ironson \& Siegel, 2005). Stress can also cause anxiety. Anxiety is an unpleasant state of inner turmoil, often accompanied by nervous behavior, such as pacing back and forth, somatic complaints and rumination. It is the subjectively unpleasant feelings of dread over something unlikely to happen, such as the feeling of imminent death. Anxiety is feeling unrealistic fear, worry, and uneasiness, usually generalized and unfocused. It is often accompanied by restlessness, fatigue, problems in concentration, and muscular tension (Anderson, Cohen, Naumova, \& Must, 2006).

Senior school learners need to make significant decisions about their subject choice, and future careers. While much guidance is provided by teachers and parents, as well as external bodies, there has been little study done on what effect the levels of anxiety and stress learners may feel plays on decision-making. By determining both the felt levels of anxiety and stress, as well as the current decision-making skills learners use, the guidance offered to learners could be improved. We were interested to answer the question: Does anxiety and stress levels 
influence the decision making styles of senior learners?

\section{Methods}

As part of a school science fair project, 157 senior learners (Grades 10-12) participated in this study. The sample of participants was identified through three sampling processes which were (1) a convenient sample as the researchers were based at the school, (2) randomly selected two classes per grade and (3) a final self-selected sample of 157 participants. Participants were invited to voluntarily participate in the study. These learners were thus in grades 10 (39\%), 11 (42\%) and 12 (19\%) with the majority being in Grade 11. The mean age for the sample of participants was 16.34 years.

\subsection{Instruments}

Participants were asked to complete the following questionnaires:

The Flinders Decision Making Questionnaire (Mann, 2004)

This questionnaire consisted of six subscales and is described as:

Vigilance - 6 items (Sample item: 'When making decisions I like to collect lots of information') Each of the six vigilance items relates to a step in sound decision making, such as defining goals, collecting information, considering alternatives, and checking alternatives; Hyper-vigilance consists of 5 items (sample item: 'I feel as if I'm under tremendous pressure when making decisions'). Defensive avoidance consists of 5 items (sample item: 'I avoid making decisions'). The remaining three scales, each comprising five items, measure different aspects of defensive avoidance, that is rationalization ('After a decision is made, I spend a lot of time convincing myself it was correct'), buck-passing ('I prefer to leave decisions to others'), and procrastination ('I put off making decisions'). The respondent responds to the items by checking 'True for me' (score 2), 'Sometimes true' (score 1), or 'Not true for me' (score 0).

The reliability of the instruments were assessed and showed good reliability with the following alphas: Decision-making Styles .75.

Depression, Anxiety and Stress Scale (DASS, Lovibond \& Lovibond, 2004)

The main purpose of the DASS is to isolate and identify aspects of emotional disturbance; for example, to assess the degree of severity of the core symptoms of depression, anxiety or stress. This scale consists of 42 items but a shorted version of 21 items is available. For this study, 14 items from the 21 items of the DASS were used to only determine anxiety and stress. The Anxiety scale assesses autonomic arousal, skeletal muscle effects, situational anxiety and subjective experience of anxious affect. The Stress scale's subscales highlight levels of non-chronic arousal through difficulty relaxing, nervous arousal and being easily upset/agitated, irritable/over-reactive and impatient.

The reliability of the instruments were assessed and showed good reliability with the 
following alphas: Anxiety .87 and Stress .64.

\subsection{Procedure}

Permission to conduct this study was provided by the management of the school and tutors of each class within the ambit of the school project. Once permission was obtained the tutor period was used to collect the data. Learners were informed about the purpose of the study and what the aim of the study was. They were also explained the ethical parts of the research such as anonymity and confidentiality of the information, as well as the right to withdrawal. The participants were asked to complete the questionnaires. The questionnaire was self-administered in approximately 20 minutes.

\subsection{Data Analysis}

The information from the questionnaires was entered into the Statistical Package for Social Science (SPSS v21). The data was coded and cleaned. Variables were created according to the requirements of the different scales and subscales. For anxiety and stress, 7 items for each scale were added together to create the variables. For decision-making, subscales were created by adding the items for each subscale as indicated in the manual. These subscales were coded as follows:

$\mathrm{V}=$ Vigilance (6 items with a maximum score of 12)

$\mathrm{H}=$ Hypervigilance (5 items with a maximum score of 10)

$\mathrm{D}=$ Defensive Avoidance (5 items with a maximum score of 10)

$\mathrm{B}=$ Buck-Passing (5 items with a maximum score of 10)

$\mathrm{P}=$ Procrastination (5 items with a maximum score of 10)

$\mathrm{R}=$ Rationalization (5 items with a maximum score of 10)

Frequencies and mean scores were used for descriptive statistics. Correlations and regression analysis were used for inferential statistics. Correlations were used to determine if relationships between variables are significant, positive and negative for the purposes of hypotheses testing. 


\section{Results}

Table 1. Sample Characteristics

\begin{tabular}{|c|c|}
\hline Variables & $\mathbf{n}=\mathbf{1 5 7}$ \\
\hline \multicolumn{2}{|c|}{ Gender } \\
\hline Male & 67 (42.7\%) \\
\hline Female & $90(57.3 \%)$ \\
\hline \multicolumn{2}{|c|}{ Parental Marital Status } \\
\hline Married & $116(73.9 \%)$ \\
\hline $\begin{array}{l}\text { Live together but } \\
\text { not married }\end{array}$ & 3 (1.9\%) \\
\hline $\begin{array}{l}\text { Single and never } \\
\text { been married }\end{array}$ & $5(3.2 \%)$ \\
\hline $\begin{array}{l}\text { Single because } \\
\text { he/she is widowed }\end{array}$ & $15(9.6 \%)$ \\
\hline $\begin{array}{l}\text { Single because } \\
\text { he/she is divorced }\end{array}$ & $16(10.2 \%)$ \\
\hline
\end{tabular}

\begin{tabular}{lll}
\hline \multicolumn{3}{c}{ Ethnicity } \\
\hline Coloured & 95 & $(60.5 \%)$ \\
Black African & 17 & $(10.8 \%)$ \\
White & 32 & $(20.4 \%)$ \\
Indian/Asian & 11 & $(7 \%)$ \\
\hline
\end{tabular}

\section{Living arrangements}

Both Parents

117 (74.5\%)

Only mother

$29 \quad(18.5 \%)$

Only father

$3 \quad(1.9 \%)$

Guardian/caregiver

$7 \quad(4.5 \%)$

\section{Home Language}

\begin{tabular}{lll}
\hline English & 133 & $(84.7 \%)$ \\
Afrikaans & 8 & $(5.1 \%)$ \\
IsiXhosa & 8 & $(5.1 \%)$ \\
Other & 8 & $(5.1 \%)$
\end{tabular}

Table 1 shows that the majority of participants were aged 16, female (57.3\%), identified themselves as Coloured (60.5\%), spoke English as a home language (84.7\%) and lived with both parents (74.5\%). 
Table 2. Anxiety and Stress Levels of Senior Learners at PHS

\begin{tabular}{lccccc}
\hline & \multicolumn{5}{c}{ Total Sample } \\
\hline Variables & $\boldsymbol{N}$ & Minimum & Maximum & Mean & SD \\
\hline Stress & 157 & .00 & 21.00 & 7.83 & 5.19 \\
Anxiety & 157 & .00 & 21.00 & 7.64 & 4.83 \\
\hline
\end{tabular}

Responses were on a Likert Scale with $0=$ Did not apply to me at all to $3=$ Applied to me very much.

Table 2 shows that the anxiety $(M=7.64, S D=4.83)$ and stress $(M=7.83, S D=5.19)$ levels of the senior learners at PHS were low.

Table 3. Gender: Anxiety and Stress Levels of Senior Learners at PHS

\begin{tabular}{lccccc}
\hline Variables & $\boldsymbol{N}$ & Minimum & Maximum & Mean & SD \\
\hline \multirow{2}{*}{ Stress } & 90 & .00 & 19.00 & 8.63 & 4.52 \\
\multirow{4}{*}{ Anxiety } & $(67)$ & $(.00)$ & $(21.00)$ & $(6.30)$ & $(4.94)$ \\
& 90 & .00 & 19.00 & 8.89 & 4.91 \\
& $(67)$ & $(.00)$ & $(21.00)$ & $(6.42)$ & $(5.25)$ \\
\hline
\end{tabular}

Responses were on a Likert Scale with $0=$ Did not apply to me at all to $3=$ Applied to me very much. Males are indicated in parentheses.

The results in Table 3 show that male senior learners had lower levels of anxiety and stress than female senior learners.

Table 4. Decision-Making Styles of Senior Learners at PHS

\begin{tabular}{lccccc}
\hline Variables & $\boldsymbol{N}$ & Minimum & Maximum & Mean & SD \\
\hline Buck-passing & 144 & .00 & 10.00 & 3.89 & 2.53 \\
Hypervigilant & 144 & .00 & 10.00 & 5.24 & 2.14 \\
Rational & 146 & .00 & 10.00 & 4.74 & 2.26 \\
Vigilant & 146 & 2.00 & 12.00 & 8.08 & 2.90 \\
Defensive & 145 & .00 & 10.00 & 4.06 & 2.35 \\
Procrastinating & 144 & .00 & 10.00 & 4.38 & 2.41 \\
\hline
\end{tabular}

Responses were on a Likert Scale with $0=$ Not true for me to $3=$ True for me.

The results in Table 4 show that the most prevalent decision-making style was vigilant decision-making style $(M=8.08, S D=2.90)$, which is described as defining goals, collecting information, considering alternatives, and checking alternatives. Buck-passing decision-making style was the least prevalent $(M=3.89, S D=2.53)$, which was leaving decisions to others. 
Table 5. Gender: Decision-Making Styles of Senior Learners at PHS

\begin{tabular}{llllcc}
\hline Variables & \multicolumn{1}{c}{$\boldsymbol{N}$} & Minimum & Maximum & Mean & SD \\
\hline \multirow{4}{*}{ Buck-passing } & 87 & & & 3.83 & 2.65 \\
& $(57)$ & .00 & 10.00 & $(3.98)$ & $(2.36)$ \\
Hypervigilant & 86 & & 10.00 & 5.47 & 2.03 \\
& $(58)$ & .00 & $(9.00)$ & $(4.90)$ & $(2.27)$ \\
Rational & 87 & & & 4.48 & 2.18 \\
& $(59)$ & .00 & 10.00 & $(5.20)$ & $(2.32)$ \\
Vigilant & 87 & & & 8.16 & 2.79 \\
& $(59)$ & 2.00 & 12.00 & $(7.97)$ & $(3.07)$ \\
Defensive & 87 & & & 4.08 & 2.39 \\
& $(58)$ & .00 & 10.00 & $(4.03)$ & $(2.31)$ \\
Procrastinating & 87 & & 10.00 & 4.17 & 2.45 \\
\hline
\end{tabular}

Responses were on a Likert Scale with $0=$ Not true for me to $3=$ True for me. Males are indicated in parentheses.

Table 5 shows that the most prevalent decision-making style was a vigilant decision-making style, which is described as defining goals, collecting information, considering alternatives, and checking alternatives. This was followed by hypervigilant decision-making for females $(M=5.47, S D=2.03)$ and a rational decision-making style for males $(M=5.20, S D=2.32)$. Buck-passing decision-making style was the least prevalent, which was leaving decisions to others.

Table 6. Correlations between the variables for the total sample

\begin{tabular}{lcc}
\hline & Anxiety & Stress \\
\hline $\begin{array}{l}\text { 1. Buckpassing } \\
\text { 2. Hypervigilant }\end{array}$ & $.22^{* *}$ & $.18^{*}$ \\
3. Rational & & \\
4. Vigilant & $.17^{*}$ & $.78^{* *}$ \\
5. Defensive & & \\
6. Procrastinating & \\
7. Anxiety & \\
8. Stress & \\
*. Correlation is significant at the 0.05 level (2-tailed). & \\
**. Correlation is significant at the 0.01 level (2-tailed). &
\end{tabular}

Table 6 suggests that there are significant correlations between the variables. Anxiety has a significant positive relationship with a hypervigilant decision-making style $(r=.22 ; p<0.01)$ and defensive decision-making style $(r=.17 ; p<0.05)$. Stress has a significant positive relationship with a hypervigilant decision-making style $(r=.18 ; p<0.05)$ and with anxiety $(r$ $=.78 ; p<0.01)$ 
Table 7. Correlations between the variables for Males and Females

\begin{tabular}{lc}
\hline & Anxiety \\
\hline 1. Buckpassing & $.25^{*}$ \\
2. Hypervigilant & \\
3. Rational & $.23^{*}$ \\
4. Vigilant & $.25^{*}$ \\
5. Defensive & \\
6. Procrastinating & $.76^{* *}$ \\
7. Anxiety & $\left(.78^{* *}\right)$ \\
\end{tabular}

*. Correlation is significant at the 0.05 level (2-tailed).

**. Correlation is significant at the 0.01 level (2-tailed).

Males indicated in parentheses.

Table 7 suggests that there are significant correlations between the variables. Anxiety has a significant positive relationship with a hypervigilant decision-making style $(r=.25 ; p<0.05)$, defensive decision-making style $(r=.23 ; p<0.05)$, a procrastinating decision-making style $(r$ $=.25 ; p<0.05)$ and stress $(r=.76 ; p<0.01)$ for females. For males, only anxiety was found to have a significant positive relationship with stress $(r=.78 ; p<0.01)$.

\section{Discussion}

The aim of this study was to determine the influence of anxiety and stress on the decision-making styles of senior learners.

A vigilant decision-making style was the most prevalent, which is described as defining goals, collecting information, considering alternatives, and checking alternatives. We assumed that some learners would use a rational decision making style, which would mean that after making decision, learners would spend lots of time convincing themselves it was correct, rather than looking for all the facts. We also assumed that some learners would use a procrastinating decision-making style, which means they put off making decisions. For this study, hypothesis 1 was proven to not be true. In using a vigilance decision-making style, the decision maker clarifies objectives to be achieved by the decision, canvasses an array of alternatives, searches painstakingly for relevant information, assimilates information in an unbiased manner, and evaluates alternatives carefully before making a choice. Vigilance could be similar as to the suggestions of Janis and Mann (1997) in which vigilance is considered an appropriate way to make decisions. Thus, it seems that senior learners use an appropriate decision-making style.

The stress and anxiety levels of the participants were not considered to be high since they scored below the mid-point of 10.5. The correlations show that an increase in anxiety and stress could influence an increase in hypervigilant decision-making styles. Furthermore, when 
only anxiety increases, there could be an increase in defensive decision-making styles because the relationships are significantly positive. Hypervigilant decision-making is defined by Janis and Mann (1977) as frantically searching for a way out of dilemmas. Due to time pressure, the decision maker impulsively seizes upon hastily forced solutions that seem to promise immediate relief. In using this style of decision-making, the decision-maker does not consider the consequences of the choices due to being emotionally excited and offering limited attention. In its more extreme form, hyper-vigilance is a 'panic'-like state in which the decision maker wavers between unpleasant alternatives. Hypervigilance is associated with severe emotional stress. This is the same as that stated by Keinan (1987) which highlights that under severe stress, a person can become hypervigilant and this is seen in hasty, disorganized, and an incomplete evaluation of information leading to faulty decisions and post-decisional regret. This then could have implications for examinations and tests if there are high levels of stress and anxiety.

As expected in this study stress influences anxiety because there is a significantly positive relationship. This is understandable as both emotions are negative emotions for the human body. In psychology, stress is a feeling of strain and pressure. Symptoms may include a sense of being overwhelmed, feelings of anxiety, overall irritability, insecurity, nervousness, social withdrawal, loss of appetite, depression, panic attacks, exhaustion, high or low blood pressure, skin eruptions or rashes, insomnia, lack of sexual desire (sexual dysfunction), migraine, gastrointestinal difficulties (constipation or diarrhea), and for women, menstrual symptoms (Cohen, Janicki-Deverts, Miller, 2007). Anxiety is a mood. When it becomes a mental disorder, that is, characterized by excessive, uncontrollable and often irrational worry about everyday things that is disproportionate to the actual source of worry, it is diagnosed as generalized anxiety disorder (GAD). Anxiety occurs in situations only perceived as uncontrollable or unavoidable, but not realistically so. David Barlow defines anxiety as "a future-oriented mood state in which one is ready or prepared to attempt to cope with upcoming negative events," and that it is a distinction between future and present dangers which divides anxiety and fear (Barlow, 2000).

In this study anxiety is also related to a defensive avoidance decision-making style. The decision maker escapes conflict by procrastinating, shifting responsibility to someone else, or constructing wishful rationalizations to bolster the least objectionable alternative (Janis \& Mann, 1977). Each of these expressions of defensive avoidance is associated with incomplete and often biased evaluation of information, leading in turn to faulty decisions. Defensive avoidance is associated with high stress. Similarly, Miu, Heilman \& Houser (2008) found that anxiety impaired decision-making. The results of hypothesis 2 and 3 are only partly proven to be true.

\subsection{Male and female differences}

An interesting outcome of this study was that there were male and female differences in experiencing stress and anxiety. Males had lower stress and anxiety levels than females. The majority of both males and females had vigilant decision-making styles. This was followed by hypervigilant decision-making styles for females and rational decision-making styles for 
males. This could be explained by the correlations because only female anxiety was associated with the negative decision-making styles. Research shows that women are at a greater risk of anxiety (Kohrt \& Worthman, 2009). Furthermore, in a study comparing the effects of anxiety and making decisions between males and females, men, both low and high anxiety groups showed impaired decision-making compared to medium anxiety individuals, whereas in women only high anxiety individuals performed poorly. Furthermore, anxiety affected decision-making in men early in the task that is in the exploration phase, as opposed to an effect on performance in women during the second part of the test that is the exploitation phase (de Visser, et al., 2010).

\section{Limitations of the study}

Although this is the first study of its kind in South Africa, the results of this study should be cautiously interpreted. This study was cross-sectional and contextual based on a school project. This means that the findings cannot be generalised to other samples. This was a very small sample but perhaps a larger sample could provide different results.

\subsection{Implications}

There are several implications of this study:

- It appears that, in general, senior learners use an appropriate decision-making style. This could be a consequence of the teaching about decision-making to the junior grades.

- $\quad$ Male learners who experience anxiety may make impulsive decisions.

- $\quad$ Female learners who experience both stress and anxiety may make impulsive decisions.

- It would be of benefit if the school curriculum included more explicit material to enable learners to identify physical stress symptoms within themselves, such as insomnia, migraine, loss of appetite, constipation or diarrhoea. Being aware of these symptoms would enable learners to be aware that they may be switching to a hypervigilance decision-making style. Guidance could also be given on how to reduce their stress to be able to return to a vigilance style of decision-making.

- In schools where stress and anxiety levels are high learners are less likely to make good academic decisions and would require more help to make appropriate decisions.

\section{Conclusion}

This study shows that senior learners are vigilant in their decision-making. In other words they review all information before making a decision. This could be linked to their low levels of stress and anxiety. This study shows a significantly positive relationship between stress and anxiety and the more negative types of decision-making styles such as hypervigilant, defensive avoidant and procrastinating in their decision-making styles. This means that senior learners using this decision-making style could be hasty in their decision-making, be 
disorganised and therefore make incorrect decisions, or they could transfer their responsibilities to someone else. This could have implications for situations when important decisions need to be made or during a test or examination. An additional outcome of this study was that there were male and female differences in the findings with females having slightly higher levels of stress and anxiety than males. Also female anxiety was associated with the more negative decision-making styles but not males.

\section{References}

Anderson, S.E., Cohen, P., Naumova, E.N., \& Must, A. (2006). Assocaition of depression and anxiety disorders with weight change in a prospective community-based study of children followed up into adulthood. Archives of Pediatrics and Adolescent Medicine, 160(3), 285-291.

Barlow, D. H. (2000). Unraveling the mysteries of anxiety and its disorders from the perspective of emotion theory. American Psychologist, 55(11), 1247-63. http://dx.doi.org/10.1037/0003-066X.55.11.1247. PMID 11280938

Cohen, S., Janicki-Deverts, D., \& Miller, GE. (2007). Psychological Stress and Disease. JAMA， 298(14)， 1685-1687. http://dx.doi.org/10.1001/jama.298.14.1685. PMID 17925521

de Vissera, L., van der Knaapa, L.J., van de Looa, A.J.A.E., van der Weerda, C.M.M., Ohla, F., \& van den Bos,R. (2010). Trait anxiety affects decision-making differently in healthy men and women: Towards gender-specific endophenotypes of anxiety. Neuropsychologia, 48, 1598-1606.

Henry, J.D., \& Crawford, J.R. (2005). The short-form version of the Depression Anxiety Stress Scales: construct validity and normative data in a large non-clinical sample. British. Journal of Clinical Psychology, 44, 227-239.

Kohrt, B.A., \& Worthman, C.M. (2009). Gender and anxiety in Nepal: The role of social support, stressful life events and structural violence. CNS Neuroscience and Therapeutics, 15(3), 237-248.

Lovibond, S.H., \& Lovibond, P.F. (2004). Manual for the Depression Anxiety Stress Scales, (2nd ed.). School of Psychology, University of New South Wales, Sydney.

Mann, L. (1982). Flinders Decision Making Questionnaire IF, unpublished questionnaire. The Flinders University of South Australia.

Keinan, G. (1987). Decision making under stress: Scanning of alternatives under Controllable and uncontrollable threats. Journal of Personality and Social Psychology, 52(3), 639-644.

Miu, A.C., Heilman, R.M., \& Houser, D. (2008). Anxiety impairs decision-making: Psychological evidence from an Iowa gambling task. Biological Psychology, 22, 
353-358.

Raghunathan, R., \& Pham, M.T. (1999). All Negative Moods Are Not Equal: Motivational Influences of Anxiety and Sadness on Decision Making. Organizational Behavior and Human Decision Processes, 79(1), 56-77.

Schneiderman, N., Ironson, G., \& Siegel, S.D. (2005). Stress and health: Psychological, behavioral and biological determinants. Annual Review of Clinical Psychology, 1, 607-628. http://dx.doi.org/10.1146/annurev.clinpsy.1.102803.144141

\section{Copyright Disclaimer}

Copyright reserved by the author(s).

This article is an open-access article distributed under the terms and conditions of the Creative Commons Attribution license (http://creativecommons.org/licenses/by/3.0/). 